\title{
Assessing a possible vulnerability to dental caries in individuals with rare genetic diseases that affect the skeletal development
}

\author{
Heloisa Vieira Prado ${ }^{10}$, Natália Cristina Ruy Carneiro², Matheus França Perazzo², \\ Mauro Henrique Nogueira Guimarães de Abreu' ${ }^{1}$ Carolina de Castro Martins ${ }^{2}$ and Ana Cristina Borges-Oliveira ${ }^{{ }^{*}}$
}

\begin{abstract}
Background: Individuals diagnosed with a rare genetic disease that affects skeletal development often have physical limitations and orofacial problems that exert an impact on oral health. The aim of the present study was to analyze the possible vulnerability to dental caries in individuals with rare genetic diseases that affect skeletal development.

Methods: A paired cross-sectional study was carried out with a sample of 140 individuals [70 with rare genetic diseases affecting skeletal development: mucopolysaccharidosis (MPS) $(n=29)$ and osteogenesis imperfecta (OI) $(n=41)$ and 70 without rare diseases] and their parents/caregivers. The participants in the first group were recruited from two reference hospitals specialized in rare genetic diseases in the city of Belo Horizonte, Brazil. All participants were examined for the evaluation of breathing type, malocclusion, dental anomalies, oral hygiene and dental caries. The parents/caregivers answered a structured questionnaire addressing the individual/behavioral characteristics and medical/dental history of the participants. Statistical analysis involved the chi-square test and multiple logistic regression analysis for the dependent variable (dental caries) $(a=5 \%)$. This study received approval from the Human Research Ethics Committee of the Universidade Federal de Minas Gerais.

Results: The mean age of the individuals was $10.34 \pm 6.55$ years (median: 9.50 years). Individuals with inadequate oral hygiene were 4.70-fold more likely to have dental caries ( $95 \% \mathrm{Cl}: 2.13-10.40)$ and those with the rare genetic diseases (MPS/OI) were 2.92-fold more likely to have dental caries (95\% Cl: 1.38-6.17).

Conclusion: Individuals with inadequate oral hygiene and those with MPS and OI had a greater chance of belonging to the group with dental caries. Based on the present findings, individuals with the rare genetic diseases may be considered vulnerable to caries.
\end{abstract}

Keywords: Rare diseases, Genetic diseases, Disabled persons, Oral health, Dental caries

\section{Background}

The World Health Organization (WHO) defines rare diseases as all diseases for which the prevalence is less than 65 cases per 100,000 inhabitants [1]. Rare diseases are characterized as debilitating and chronically degenerative and require continuous medical follow up.

\footnotetext{
* Correspondence: anacboliveira7@gmail.com

${ }^{1}$ Department of Dental Public Health, Faculty of Dentistry, Universidade Federal de Minas Gerais, Av. Antônio Carlos, 6627. Campus Pampulha /, Belo Horizonte, MG 31270-901, Brazil

Full list of author information is available at the end of the article
}

Affected individuals often have impaired physical, mental, sensorial and behavioral capacities, which can compromise their autonomy with regard to performing activities of daily living [2-6].

Mucopolysaccharidoses (MPS) and osteogenesis imperfecta (OI) are two rare genetic diseases that compromise skeletal development and affect general health. The two diseases lead to dental problems. Studies show that malocclusion, tooth agenesis, tooth rotation and microdontia are common in this population. These diseases are also associated with alterations in genes that

(c) The Author(s). 2019 Open Access This article is distributed under the terms of the Creative Commons Attribution 4.0 International License (http://creativecommons.org/licenses/by/4.0/), which permits unrestricted use, distribution, and 
regulate the formation of tooth enamel and dentin. Indeed developmental defects of enamel (DDE) are common in individuals with MPS and both dentinogenesis imperfecta (DI) and DDE are common in individuals with OI [7-11].

These dental problems make oral hygiene more difficult $[4,7-9,12-14]$. The low mineral content in dental tissues in interaction with environmental factors may favor the occurrence of dental caries $[15,16]$. Moreover, studies have suggested that access to dental services is more difficult for individuals with special needs $[9,10$, 17-20]. The difficulty in adequately performing oral hygiene due to the limitations imposed by disease and a lack of information on the part of parents or caregivers about the importance of oral health care can place individuals with special needs in a vulnerable position with regard to dental caries $[10,12,13,15,18-21]$.

The concept of vulnerability in health is based on the understanding of susceptibility to illness [12, 22, 23]. Illness is considered to arise from a set of individual, collective and contextual factors. This concept also involves the potential for coping with health problems in order to promote strategies for healthcare actions [17, 23]. In the present study, vulnerability is approached from the perspective of the expanded concept of health, exploring the more complex factors of biopsychosocial frailty that expose individuals with rare diseases to dental caries. The investigation of vulnerability provides more integrated means of assessing dental care needs taking into account the abstract and subjective elements associated with the process of becoming ill $[4,21,23]$.

Therefore, the aim of the present study was to analyze the possible vulnerability to dental caries in individuals diagnosed with rare genetic diseases that affect skeletal development.

\section{Methods}

A paired cross-sectional study was carried out with a sample of 140 individuals (70 with rare diseases and 70 without rare diseases) between two and 27 years of age and their parents/caregivers. A convenience sample was selected of individuals with two rare genetic diseases affecting skeletal development: MPS $(n=29)$ and OI $(n=41)$.

The group with rare diseases was recruited from two public hospitals in the city of Belo Horizonte, Brazil. The hospitals are reference centers for the treatment of these two diseases. Individuals without rare diseases were recruited from outpatient clinics at the same two hospitals. All hospitals belong to the public healthcare system. This study received from the Human Research Ethics Committee of the Universidade Federal de Minas Gerais (certificate numbers: 01480212.4.0000.5149 [MPS] and 03027612.7.000.5149 [OI]).
The PS program (Power and Sample Size Calculation, version 3.0, Nashville, TN, USA) was used to calculate the test power. Considering the data obtained, the probability of exposure to dental caries among the controls was $34.3 \%$ and the correlation coefficient for exposure between matched cases and controls was 0.5. The odds ratio for dental caries among the individuals with rare diseases compared to the control group was 4.1. Thus, the test power was $100 \%$, with a $5 \%$ margin of type I error.

\section{Data collection}

Data collection involved oral examinations of the participants and the administration of a questionnaire to parents/ caregivers addressing sociodemographic and behavioral aspects of the participants (based on Oliveira et al., 2008a [17]; 2008b [24]). The type of rare disease was identified by the patient's medical record. Economic status was determined based on the Brazilian Economic Classification Criteria (ABEP), which addresses the purchasing power and general situation of households and classifies families in A1 (highest), B1, B2, C1, C2, D and E (lowest). Classes were categorized into high (A1, B1 and B2), middle (C1 and C2) and low (D and E) [25]. Ethnicity was categorized using the criteria established by the Brazilian Institute of Geography and Statistics (IBGE) for skin color: white, black, brown or yellow [26].

The oral examinations were performed by two examiners with the patient sitting in a chair under artificial light (Petzl Zoom head lamp ${ }^{\circ}$, Petzl America, Clearfield, UT, USA). The examiners used a mouth mirror (Duflex ${ }^{\circ}$ $\left.n^{\circ} 5\right)$, Community Periodontal Index probe (Golgran', São Paulo, SP, Brazil) and appropriate personal protective equipment to avoid cross infection. Radiography was not employed.

Breathing type was determined using the oral mirror test. A double-faced oral mirror was placed under the patient's nose. If the patient was a mouth breather (either alone or with nasal breathing), the mirror would be fogged on the lower portion; if the patient had only nasal breathing, the mirror would be fogged only on the upper portion $[24,27]$.

The following malocclusions were investigated: overjet (increased/protrusion, anterior crossbite, absent), overbite (increased/deep bite, anterior open bite, absent, top) and posterior crossbite. The following dental anomalies were investigated: conical tooth, tooth agenesis, tooth rotation, DDE and DI. Tooth agenesis was considered a possible diagnosis, because the oral examination was performed only clinically. The diagnostic criteria for malocclusion and dental anomalies were based on Seow (2014) [28], Oliveira et al. (2008b) [24] and the WHO (2013b) [29]. 
The Simplified Oral Hygiene Index (OHI-S) was used to evaluate oral hygiene and was scored as follows: $0=\mathrm{Ab}$ sence of dental plaque/dental calculus; $1=$ little dental plaque/dental calculus, less than $1 / 3$ of dental surface covered; 2 = dental plaque / dental calculus covering more than $1 / 3$ and less than $2 / 3$ of the dental surface; and $3=$ dental plaque/dental calculus covering more than $2 / 3$ of dental surface. Plaque and dental calculus were evaluated separately $[17,21,30]$. The final result of the OHI-S was obtained from the sum of the codes divided by the total number of teeth examined and classified as satisfactory (0 to 1$)$, fair (1.1 to 2$)$, deficient (2.1 to 3 ) or poor ( $\geq 3.1)$. The classification was dichotomized as adequate (satisfactory and fair) or inadequate (deficient and poor).

Dental caries was assessed according to the WHO diagnostic criteria [29]. The number of decayed (presence of cavitated lesion) primary and permanent teeth was recorded.

\section{Training and calibration process}

Training and calibration exercises were performed prior to the main study and were divided into theoretical and practical steps. The theoretical step involved the analysis of images of malocclusions, dental anomalies, different levels of oral hygiene and dental caries. The practical step performed at one of the hospitals selected for the main study. Due to the limited number of individuals with MPS and OI, only individuals without rare diseases were examined during the calibration process. These individuals were not included in the final sample. The results of the examiners were compared to the findings of an experienced epidemiologist (gold standard) using the Kappa statistic. Agreement was very good, with Kappa coefficients between 0.76 and 0.98 for all conditions examined.

\section{Pilot study}

A pilot study was carried out after the calibration process involving 10 individuals with rare diseases and their respective parents/caregivers at the previously selected public hospitals. The pilot study indicated that no changes to the methodology were required. The participants in the pilot study were included in the main study.

\section{Directed acyclic graph}

Prior to the data analysis, a directed acyclic graph (DAG) was used to select the covariates for the statistical adjustments. This is a theoretical method with visual representations of causal assumptions that is increasingly used in modern epidemiology to help identify confounding factors for the causal question at hand [31].

To identify possible confounding variables in the association between the rare diseases and dental caries, individual factors (diet, oral hygiene, physical and mental disability) $[13,18,20,21,32]$ and clinical factors (malocclusion, dental anomalies and breathing type) [11, 24, 33,34 ] were included in the DAG model. Variables related to contextual and collective factors (previous dental experience, professional advice to consult a dentist, access to dental services, oral health policies, lack of experienced professionals and dental insurance) [11, 17, $19,35]$ were also included. Based on the model, there were no confounding factors in the association between the rare diseases and dental caries. As the individuals in the different groups were matched for age, sex and economic status, these variables were not incorporated into the DAG (Fig. 1).

\section{Statistical analysis}

Statistical analysis was performed using the Statistical Package for the Social Sciences (SPSS for Windows, version 21.0, IBM Inc., Amonk, NY, USA). The chi-square test was used to determine the association between the exposure (dental caries) and the independent variables $(p<0.05)$. Multiple logistic regression analysis was performed to identify the independent impact of each variable studied. The independent variables were included in the decreasing logistic model in accordance with their statistical significance $(p<0.25$; backward stepwise procedure).

\section{Results}

The age of the 140 subjects examined ranged from two to 27 years (mean: $10.34 \pm 6.55$ years; median 9.50 years). The mean age of the parents/caregivers was $37.93 \pm 9.00$ years (median: 37.00 years).

The distribution of the 70 individuals with rare diseases is represented in Fig. 2. The most frequent types of dental anomalies in the population studied were DDE, DI and tooth rotation (Fig. 3).

No significant differences between groups were found regarding sex $(p=1.000)$, age $(p=0.723)$, skin color $(p=0.859)$, parent's/caregiver's schooling ( $p=$ $0.205)$ and economic status $(p=0.301)$ (Table 1$)$.

Rare disease $(p<0.001)$ and oral hygiene $(p<0.001)$ were significantly associated with dental caries (Table 2).

Table 3 displays the results of the multiple logistic regression analysis. The variables "oral hygiene" and "rare disease" remained in the final model. Individuals with rare diseases had a 2.92-fold greater chance of belonging to the group diagnosed with dental caries (95\% CI: 1.37-6.17; $p=0.005)$ and those with inadequate oral hygiene had a 4.70 -fold greater chance of belonging to the group diagnosed with dental caries (95\% CI: 2.13-10.40; $p<0.001$ ).

\section{Discussion}

The vulnerability concept discusses the health-disease process taken in account the more complex causes associated with it $[22,23]$. The analysis of vulnerability to 


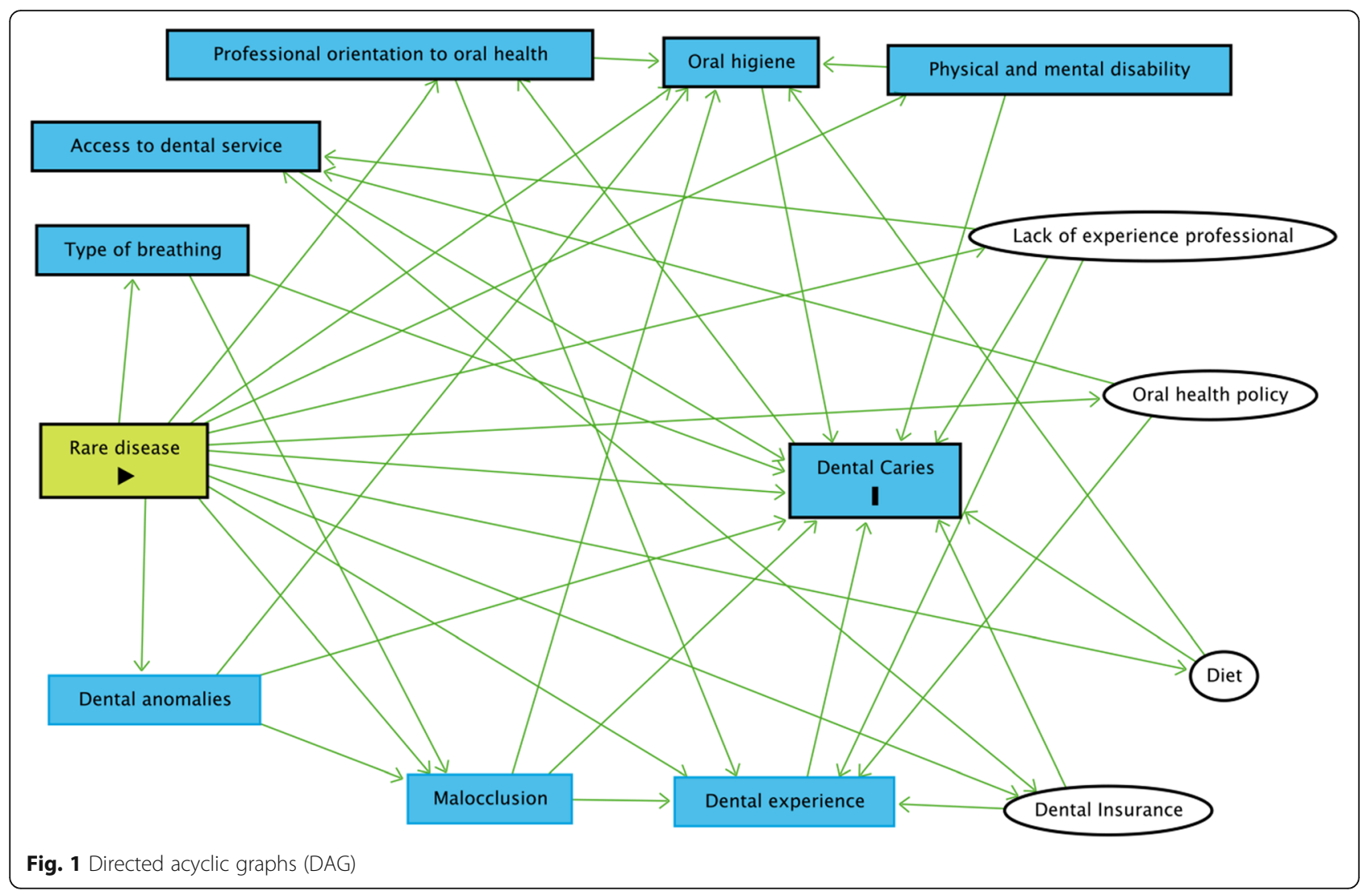

dental caries is an important point of reflection for formulating measures to ensure greater protection for vulnerable individuals. In contrast, isolated emergency actions do not modify causality.

The limitations imposed by some rare diseases can negatively impact quality of life $[2-6,9,12,14]$ and the occurrence of oral problems exacerbates this situation. Dental caries can cause acute or chronic pain, the formation of fistulas and abscesses, and tooth loss [17, 19, 20]. The consequences of untreated tooth decay can affect different aspects of life, such as activities of daily living, sleep, speech, eating, social relations and self-esteem [17, 19-21].

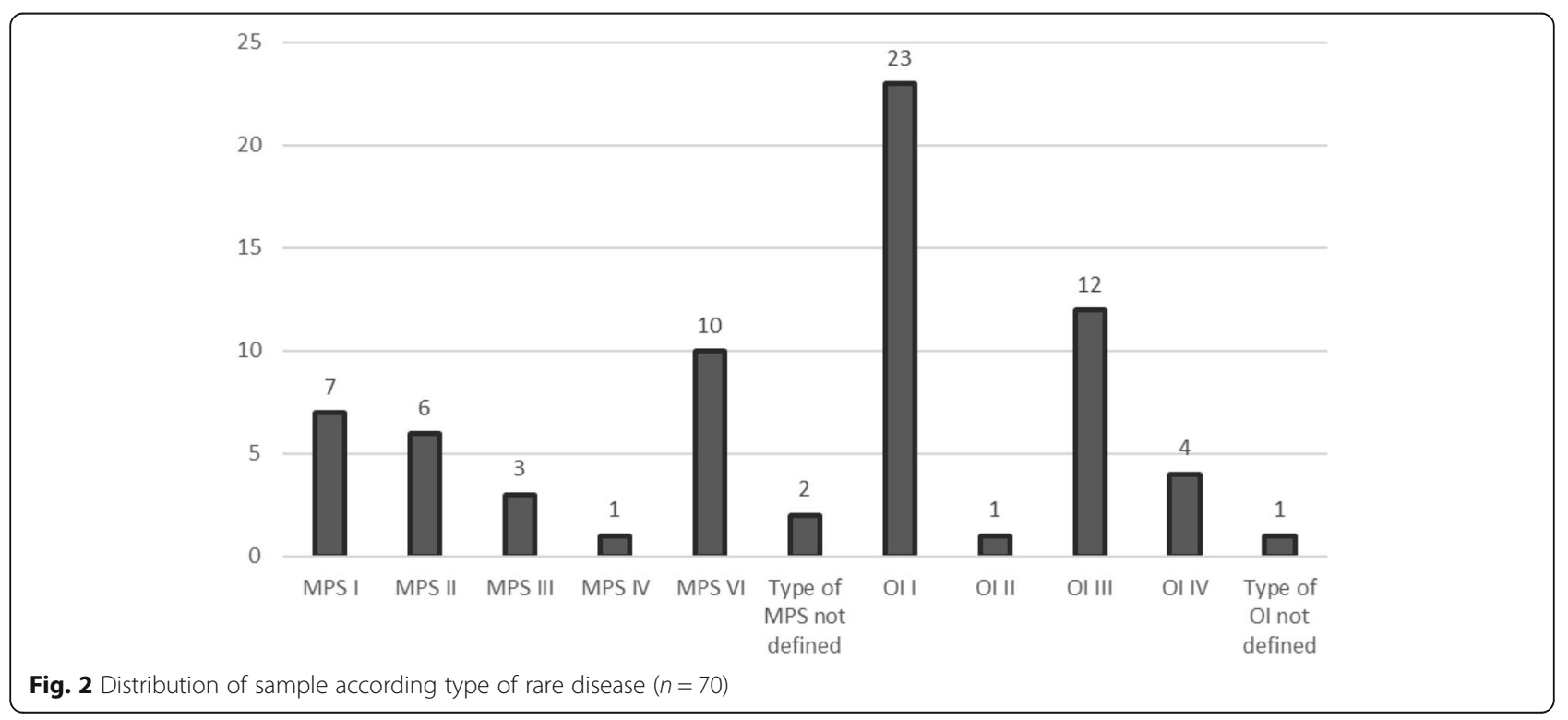




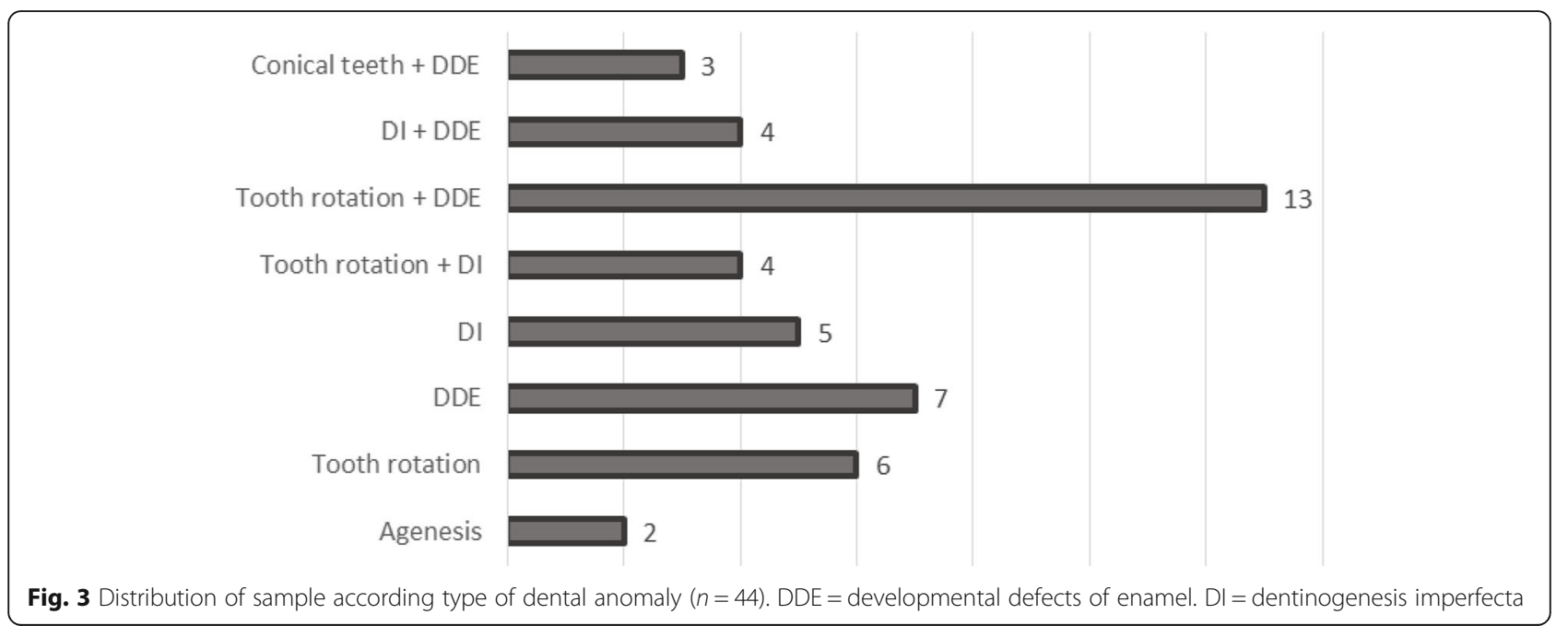

The rare genetic diseases MPS and OI were chosen for the present investigation because both affect the development of the skeletal system. Malocclusions and dental anomalies are also commonly found in this population [4, 7-11]. Furthermore, care for the patients of these conditions is offered a university hospital that is considered to be a reference center for the treatment of rare genetic diseases.

In the present study, individuals with a poor oral hygiene (with or without a rare disease) had a greater chance of belonging to the group with dental caries. The individuals with rare diseases were also more likely to belong to the group with dental caries. The influence of oral hygiene on the prevalence of dental caries has been widely discussed [36-38]. The increased chance of individuals with rare diseases having dental caries is the result of a set of factors. According to some authors, not only individual factors, but also collective and contextual factors lead to greater susceptibility to dental caries [22, 23].

A physical limitation or motor impairment in a disabled individual can lead to dependence with regard to performing activities of daily living, such as oral hygiene $[2,12,13,21]$. Moreover, parents and caregivers often

Table 1 Distribution of sample of individuals with and without rare diseases $(n=140)$

\begin{tabular}{|c|c|c|c|c|}
\hline \multirow[t]{2}{*}{ Variables } & \multicolumn{3}{|l|}{ GROUP } & \multirow{2}{*}{$\begin{array}{l}p^{-} \\
\text {value } \\
*\end{array}$} \\
\hline & $\begin{array}{l}\text { With rare diseases } \\
\mathrm{n}(\%)\end{array}$ & $\begin{array}{l}\text { Without rare diseases } \\
\mathrm{n}(\%)\end{array}$ & $\begin{array}{l}\text { Total } \\
\text { n (100\%) }\end{array}$ & \\
\hline \multicolumn{5}{|l|}{ Sex } \\
\hline Male & $42(49.2)$ & $43(50.6)$ & 85 & \multirow[t]{2}{*}{1.000} \\
\hline Female & $28(50.9)$ & $27(49.1)$ & 55 & \\
\hline \multicolumn{5}{|l|}{ Age (years) } \\
\hline $2-12$ & $44(48.4)$ & $47(51.6)$ & 91 & \multirow[t]{2}{*}{0.723} \\
\hline $13-27$ & $26(53.1)$ & $23(46.9)$ & 49 & \\
\hline \multicolumn{5}{|l|}{ Skin color } \\
\hline Black / Brown & $45(48.9)$ & $47(51.1)$ & 92 & \multirow[t]{2}{*}{0.859} \\
\hline White & $25(52.1)$ & $23(47.9)$ & 48 & \\
\hline \multicolumn{5}{|c|}{ Parent's/caregiver's education (years) } \\
\hline$\geq 8$ & $44(46.3)$ & $51(53.7)$ & 95 & \multirow[t]{2}{*}{0.205} \\
\hline$<8$ & $26(57.8)$ & $19(42.2)$ & 45 & \\
\hline \multicolumn{5}{|l|}{ Economic class } \\
\hline High $(A+B)$ & $27(56.3)$ & $21(43.8)$ & 48 & \multirow[t]{3}{*}{0.301} \\
\hline Middle (C) & $40(48.8)$ & $42(51.2)$ & 82 & \\
\hline Low $(D+E)$ & $3(30.0)$ & $7(70.0)$ & 10 & \\
\hline
\end{tabular}

${ }^{*} \mathrm{X}^{2}$ test (5\% significance level) 
Table 2 Absolute and relative frequency of sample according to prevalence of dental caries $(n=140)$

\begin{tabular}{|c|c|c|c|}
\hline Independent variables & DENTAL & RIES & Total \\
\hline & $\begin{array}{l}\text { Present } \\
\mathrm{n}(\%)\end{array}$ & $\begin{array}{l}\text { Absent } \\
\mathrm{n}(\%)\end{array}$ & $\begin{array}{l}\mathrm{n} \\
(100 \%)\end{array}$ \\
\hline
\end{tabular}

Age (years)

$\begin{array}{lllll}2-12 & 46(50.5) & 45(49.5) & 91 & 0.777 \\ 13-27 & 26(53.1) & 23(46.9) & 49 & \\ \text { Sex } & & & & \\ \text { Male } & 45(52.9) & 40(47.1) & 85 & 0.656 \\ \text { Female } & 27(49.1) & 28(50.9) & 55 & \end{array}$

Skin color

Black / Brown $\quad 53(57.6) \quad 39(42.4) \quad 92$

White $19(39.6) \quad 29(60.4) \quad 48$

Economic class

$\begin{array}{lllll}\text { Less favored }(D+E) & 6(60.0) & 4(40.0) & 10 & 0.544 \\ \text { Favored }(C) & 44(53.7) & 38(46.3) & 82 & \\ \text { Most favored }(A+B) & 22(45.8) & 26(54.2) & 48\end{array}$

Parent's/caregiver's education (years)

$\begin{array}{lllll}<8 & 27(60.0) & 18(40) & 45 & 0.163 \\ \geq 8 & 45(47.4) & 50(52.6) & 95 & \end{array}$

Rare disease

$\begin{array}{lrrrr}\text { Present } & 48(68.6) & 22(31.4) & 70 & <\mathbf{0 . 0 0 1} \\ \text { Absent } & 24(34.3) & 46(65.7) & 70 & \\ \text { Previous dental experience } & & & \\ \text { No } & 36(56.3) & 28(43.8) & 64 & 0.295 \\ \text { Yes } & 36(47.4) & 40(52.6) & 76 & \end{array}$

Professional advice to consult a dentist

Yes

$42(56.0) \quad 33(44.0)$

No

$30(46.2) \quad 35(53.8)$

75

Type of breathing

\begin{tabular}{lllll} 
Oral & $17(58.6)$ & $12(41.4)$ & 29 & 0.384 \\
Nasal & $55(49.5)$ & $56(50.5)$ & 111 & \\
Malocclusion & & & & \\
Present & $52(52.0)$ & $48(48.0)$ & 100 & 0.831 \\
Absent & $20(50.0)$ & $20(50.0)$ & 40 & \\
Dental anomaly & & & & \\
Present & $27(61.4)$ & $17(38.6)$ & 77 & 0.111 \\
Absent & $45(46.9)$ & $51(53.1)$ & 96 & \\
Oral hygiene & & & & \\
Inadequate & $41(75.9)$ & $13(24.1)$ & 54 & $<\mathbf{0 . 0 0 1}$ \\
Adequate & $30(34.9)$ & $56(65.1)$ & 86 & \\
\hline
\end{tabular}

${ }^{*}{ }^{2}$ test $(5 \%$ significance level) / bold type: statistically significant difference $(p<0.05)$ have difficulties with this activity, performing it improperly, infrequently or even not at all $[4,13,18,20,21]$.

In the present study, the results did not prove that dental anomalies and malocclusion were associated with a greater chance of dental caries vulnerability in individuals with MPS and OI or those without rare genetic diseases. However, is important to consider that previous studies showed that the presence of malocclusion and dental anomalies can lead to the retention of food scraps and the accumulation of dental plaque and can also hamper tooth brushing $[7,8,10,12-14]$.

Depending on its extent and the involvement of the organism, a rare disease can lead to a stressful routine of constant medical appointments, therapies and hospitalizations $[2,5,6,9,12,14]$. As a consequence of this and also due to a lack of information and guidance, parents/ caregivers of affected children often fail to prioritize oral health $[9,10,15,19,21]$, which constitutes a barrier to early and preventive dental care. It is therefore important for the medical team that cares for the patient with a rare disease to advise the parents/guardians to take him/ her to the dentist [12, 17, 18, 21, 22].

Previous studies suggest that the lack of oral health policies and programs targeting this portion of the population as well as limited knowledge and experience regarding the peculiarities of rare diseases make many oral health professionals feel uncomfortable and unprepared to treat these individuals $[9,10,12-14,19,33]$. This constitutes another barrier to preventive dental care and consequently increases the risk of dental caries among individuals with rare diseases.

Some limitations of the present study should be considered. First, the factors associated with greater vulnerability to dental caries in individuals with MPS and OI were not investigated. Further research is needed to better understand such association. The cross-sectional this study design impedes the inference of causal relationships. Moreover, the use of questionnaires is always accompanied by the risk of recall bias on the part of respondents. However, this study also has strengths that should be highlighted. The use of a matched control group without rare diseases minimizes the possible influence of the matched characteristics on the association between the dependent and independent variables. The authors also used a DAG to identify possible confounding factors and explore the influence of individual, collective and contextual factors on vulnerability to dental caries.

It is certainly of great importance to reflect on vulnerability to dental caries among individuals with rare diseases, since such patients are a small part of the general population and do not enjoy the same visibility in terms of preventive measures implemented by public health programs. The greater commitment to general health 
Table 3 Multiple logistic regression models explaining prevalence of dental caries in individuals with and without rare diseases $(n=$ 140)

\begin{tabular}{|c|c|c|c|c|}
\hline Dependent variable & Independent variables & OR (95\% Cl) Crude & OR (95\% Cl) Adjusted & $p$-value \\
\hline \multirow[t]{2}{*}{ Dental caries } & Oral hygiene (Inadequate) & $4.57(2.06-10.16)$ & $4.70(2.13-10.40)$ & $<0.001$ \\
\hline & Rare disease (Present) & $2.69(1.21-5.97)$ & $2.92(1.38-6.17)$ & 0.005 \\
\hline
\end{tabular}

OR Odds ratio, $\mathrm{Cl}$ Confidence interval

bold type: statistically significant difference $(p<0.05)$

care often leads to the neglecting of dental care needs. The lack of referral and orientation from other health professionals can aggravate the oral health status of these individuals, who also occupy an unfavorable position in terms of access to health services and they are less likely to receive dental care compared to the general population. This is presumably due to their physical limitations as well as difficulties oral health professionals face when treating these patients.

The study of vulnerability to dental caries allows theoretical approximations that are not restricted to individual behavior and the biomedical approach. It is necessary to strengthen integral care for individuals with rare diseases, ensuring access to dental services through public policies and professional training. Professionals who treat patients with rare diseases should advise parents and caregivers regarding the importance of caring for their children's oral health.

\section{Conclusion}

Individuals with inadequate oral hygiene and individuals with MPS and OI had a greater chance of belonging to the group with dental caries. Based on these findings, individuals with the rare genetic diseases studied may be considered vulnerable to caries.

\section{Abbreviations}

DDE: Developmental defects of enamel; DI: Dentinogenesis imperfecta; MPS: Mucopolysaccharidosis; Ol: Osteogenesis imperfecta

\section{Acknowledgments}

Not applicable.

\section{Authors' contributions}

HVP was involved in interpretation of the data and writing the manuscript. NCRC, MFP and CCM took part in the concept, design, a critical review of the intellectual content and writing of the article. MHNGA and ACBO took part in the design, data analysis, data interpretation and writing of the article. All authors read and approved the final manuscript.

\section{Funding}

This study was funded in part by the Brazilian fostering agencies Conselho Nacional de Desenvolvimento Científico e Tecnológico (CNPq [Council of Scientific and Technological Development]), Coordenação de Aperfeiçoamento de Pessoal de Nivel Superior (CAPES [Coordination for the Advancement of Higher Education Personnel]) -(Finance Code 001), Fundação de Amparo a Pesquisa do Estado de Minas Gerais (FAPEMIG [State of Minas Gerais Research Foundation]) and Pró-Reitoria de Pesquisa da Universidade Federal de Minas Gerais (PRPq/UFMG [Dean's Office for Research Projects of the Federal University of Minas Gerais]).

\section{Availability of data and materials}

All data generated and analyzed during this study are included in this published article.

\section{Ethics approval and consent to participate}

This study received approval from the Human Research Ethics Committee of the Universidade Federal de Minas Gerais [certificate numbers: 01480212.4.0000.5149 (MPS) and 03027612.7.000.5149(OI)] and written informed consent was obtained from all patients.

\section{Consent for publication}

The participants or their parents/caregivers gave a written consent for the publication of their anonymous clinical data.

\section{Competing interests}

The authors declare that they have no competing interests.

\section{Author details}

${ }^{1}$ Department of Dental Public Health, Faculty of Dentistry, Universidade Federal de Minas Gerais, Av. Antônio Carlos, 6627. Campus Pampulha /, Belo Horizonte, MG 31270-901, Brazil. 'Department of Pediatric Dentistry and Orthodontics, Faculty of Dentistry, Universidade Federal de Minas Gerais, Belo Horizonte, Brazil.

Received: 12 March 2019 Accepted: 4 June 2019

Published online: 18 June 2019

References

1. World Health Organization (WHO). Priority medicines for Europe and the world 2013, 2013. http://www.who.int/medicines/areas/priority_medicines/ Ch6_19Rare.pdf. Accessed 16 May 2018.

2. Raluy-Callado M, Chen WH, Whiteman DA, Fang J, Wiklund I. The impact of hunter syndrome (mucopolysaccharidosis type II) on health-related quality of life. Orphanet J Rare Dis. 2013:8:101.

3. Toupenay S, Razanamihaja N, Berdal A. Boy-Lefèvre ML. Rare diseases with oral components: care course and quality of life. Community Dent Health. 2013;30(1):10-4.

4. Molina-García A, Castellanos-Cosano L, Machuca-Portillo G, Posada-de la Paz M. Impact of rare diseases in oral health. Med Oral Patol Oral Cir Bucal. 2016;21(5):e587-94.

5. Slade A, Isa F, Kyte D, Pankhurst T, Kerecuk L, Ferguson J, Lipkin G, et al. Patient reported outcome measures in rare diseases: a narrative review. Orphanet J Rare Dis. 2018;13:61.

6. Vanz AP, van de Sande Lee J, Pinheiro B, Zambrano M, Brizola E, da Rocha NS, et al. Health-related quality of life of children and adolescents with osteogenesis imperfecta: a cross-sectional study using Peds $\mathrm{Q}^{\mathrm{TM}}$. BMC Pediatr. 2018;18:95.

7. Rizkallah J, Schwartz S, Rauch F, Glorieux F, Vu DD, Muller K, Retrouvey JM. Evaluation of the severity of malocclusions in children affected by osteogenesis imperfecta with the peer assessment rating and discrepancy indexes. Am J Orthod Dentofac Orthop. 2013;143:336-41.

8. Ribeiro EM, Fonteles CS, Freitas AB, da Silva Alves KS, Monteiro AJ, da Silva CA. A clinical multicenter study of orofacial features in 26 brazilian patients with different types of mucopolysaccharidosis. Cleft Palate Craniofac J. 2015; 52(3):352-8.

9. Tosi LL, Oetgen ME, Floor MK, Huber MB, Kennelly AM, McCarter RJ, et al. Initial report of the osteogenesis imperfecta adult natural history initiative. Orphanet J Rare Dis. 2015;10:146.

10. Carneiro NCR, Deps TD, França EC, Valadares ER, Pordeus IA, Borges-Oliveira AC. Oral health of children and adolescentes with mucopolysaccharidosis and mother's sense of coherence. Spec Care Dent. 2017;37(5):223-9. 
11. Andersson K, Dahllöf G, Lindahl K, Kindmark A, Grigelioniene G, Åström E, et al. Mutations in COL1A1 and COL1A2 and dental aberrations in children and adolescents with osteogenesis imperfecta - a retrospective cohort study. PLoS One. 2017;12(5):e0176466.

12. Scarpa M, Almássy Z, Beck M, Bodamer O, Bruce IA, De Meirleir L, et al. Mucopolysaccharidosis type II: European recommendations for the diagnosis and multidisciplinary management of a rare disease. Orphanet $J$ of Rare Dis. 2011;6:72.

13. Sjögreen L, Andersson-norinder J, Bratel J. Oral health and oromotor function in rare diseases - a database study. Swed Dent J. 2017;39(1):23-7.

14. Hendriksz CJ, Berger KI, Lampe C, Kircher SG, Orchard PJ, Southall R, et al. Health-related quality of life in mucopolysaccharidosis: looking beyond biomedical issues. Orphanet J Rare Dis. 2016;11:119.

15. Wang X, Willing MC, Mazazita ML, Wendell S, Warren JJ, Broffitt B, et al. Genetic and environmental factors associated with dental caries in children: the lowa fluoride study. Caries Res. 2012;46(3):177-84.

16. Vargas-Ferreira F, Salas MM, Nascimento GG, Tarquinio SB, Faggion CM Jr, Peres MA, et al. Association between developmental defects of enamel and dental caries: a systematic review and meta-analysis. J Dent. 2015;43(6):619-28.

17. Oliveira AC, Czeresnia D, Paiva SM, Campos MR, Ferreira EF. Utilization of oral health care for Down syndrome patients. Rev Saúde Pública. 2008a; 42(4):693-9 Portuguese.

18. Anders PL, Davis EL. Oral health of patients with intellectual disabilities: a systematic review. Spec Care Dent. 2010;30(3):110-7.

19. Liu Z, Yu D, Luo W, Yang J, Lu J, Gao S, et al. Impact of oral health behaviors on dental caries in children with intellectual disabilities in Guangzhou, China. Int J Environ Res Public Health. 2014;11(10):11015-27.

20. Braúna AP, Abreu MH, Resende VL, Castilho LS. Risk factors for dental caries in children with developmental disabilities. Braz Oral Res. 2016;30(1):e79.

21. Teixeira SA, Santos PCM, Batista AR, Albuquerque BN, Vasconcelos M, Borges-Oliveira AC. Assessment of oral hygiene in mentally disabled children. Rev Odonto Cienc. 2015:30(3):65-70.

22. Mattheus DJ. Vulnerability related to oral health in early childhood: a concept analysis. J Adv Nurs. 2010;66(9):2116-25

23. Malagón-Oviedo RA, Czeresnia D. The concept of vulnerability and its biosocial nature. Interface (Botucatu). 2015;19(53):237-49 Portuquese.

24. Oliveira AC, Paiva SM, Campos MR, Czeresnia D. Factors associated with malocclusions in children and adolescents with Down syndrome. Am J Orthod Dentofac Orthop. 2008b;133:489.e1-489 e8.

25. Associação Brasileira de Empresas de Pesquisa (ABEP). Novo Critério de Classificação Econômica Brasil. São Paulo: Associação Brasileira de Empresas de Pesquisa (ABEP); 2018. http://www.abep.org/criterio-brasil. Accessed 16 May 2018

26. Instituto Brasileiro de Geografia e Estatística (IBGE). Características étnico-raciais da população: um estudo das categorias de classificação de cor ou raça. Rio de Janeiro: Associação Brasileira de Empresas de Pesquisa (ABEP); 2011. http:// portal.mte.gov.br/data/files/8A7C816A316B688101318AB565C54F14/ PCERP2008.pdf. Accessed 29 Oct 2016

27. Vig KWL. Nasal obstruction and facial growth: the strength of evidence for clinical assumptions. Am J Orthod Dentofac Orthop. 1998;113:603-11.

28. Seow WK. Developmental defects of enamel and dentine: challenges for basic science research and clinical management. Aust Dent J. 2014;59(1):143-54.

29. World Health Organization (WHO). Oral Health Surveyes Basic methods, 6th edn. Geneva: Word Health Organization; 2013. http://apps.who.int/iris/bitstrem/ 10665/97035/1/9789241548649_eng.pdf?ua=1. Accessed 16 May 2018

30. Greene JC, Vermilion JR. The simplified oral hygiene index. J Am Dent Assoc. 1964;56:7-15.

31. Akinkugbe AA, Sharma S, Ohrbach R, Slade GD, Poole C. Directed acyclic graphs for oral disease research. J Dent Res. 2016;95(8):853-9.

32. Petrovic BB, Peric TO, Markovic DLJ, Bajkin BB, Petrovic D, Blagojevic DB, et al. Unmet oral health needs among persons with intellectual disability. Res Dev Disabil. 2016:59:370-7.

33. Chang J, Kim HY. Does caries risk assessment predict the incidence of caries for special needs patients requiring general anesthesia? Acta Odontol Scand. 2014;72(8):721-8.

34. Feldens CA, Dos Santos Dullius Al, Kramer PF, Scapini A, Busato AL, VargasFerreira F. Impact of malocclusion and dentofacial anomalies on the prevalence and severity of dental caries among adolescents. Angle Orthod. 2015;85(6):1027-34.
35. Sohn W, Ismail A, Amaya A, Lepkowski J. Determinants of dental care visits among low-income African-American children. J Am Dent Assoc. 2007; 138(3):309-18.

36. Holmes RD. Tooth brushing frequency and risk of new carious lesions. Evid Based Dent. 2016;17(4):98-9.

37. Kumar S, Tadakamadla J, Johnson NW. Effect of toothbrushing frequency on incidence and increment of dental caries: a systematic review and metaanalysis. J Dent Res. 2016;95(11):1230-6.

38. Stein C, Santos NML, Hilgert JB, Hugo FN. Effectiveness of oral health education on oral hygiene and dental caries in schoolchildren: systematic review and meta-analysis. Community Dent Oral Epidemiol. 2018:46(1):30-7.

\section{Publisher's Note}

Springer Nature remains neutral with regard to jurisdictional claims in published maps and institutional affiliations.
Ready to submit your research? Choose BMC and benefit from:

- fast, convenient online submission

- thorough peer review by experienced researchers in your field

- rapid publication on acceptance

- support for research data, including large and complex data types

- gold Open Access which fosters wider collaboration and increased citations

- maximum visibility for your research: over $100 \mathrm{M}$ website views per year

At BMC, research is always in progress.

Learn more biomedcentral.com/submissions 